\title{
IDENTIFIKASI SISTEM TANAM DAN VARIETAS PADI YANG DIKEMBANGKAN PETANI DI KABUPATEN PEMALANG
}

\author{
STUDY OF PLANTING SYSTEM AND RICE VARIETIES \\ THAT DEVELOPED BY FARMERS IN PEMALANG REGENCY, CENTRAL JAVA, \\ INDONESIA
}

\author{
Alfina Handayani \\ Badan Perencanaan Pembangunan Penelitian dan Pengembangan Daerah (BAPPEDA) \\ Provinsi Jawa Tengah \\ E-mail: alfinahandayani16@gmail.com
}

\begin{abstract}
ABSTRAK
Peningkatan produktivitas padi masih menjadi prioritas utama Pemerintah Indonesia untuk memenuhi kebutuhan pangan masyarakat, namun masih terdapat sejumlah kendala terutama dari sisi adopsi teknologi oleh petani. Penelitian ini bertujuan mengetahui kondisi budidaya petani terutama dari sisi sistem tanam, varietas yang dikembangkan dan alasan pemilihan varietas di tiga tipe topografi lahan yang berbeda (rendah, menengah, tinggi). Pengambilan sampel dilakukan secara purposif dengan jumlah sampel seluruhnya ada 45 petani yang membudidayakan padi. Pengumpulan data meliputi pengamatan langsung (observasi) dan wawancara terstruktur. Data selanjutnya dianalisis secara deskriptif. Hasil penelitian menunjukkan bahwa sistem tanam yang berkembang di tiga tipe topografi adalah sistem tanam tegel, teknologi seperti jajar legowo dan SRI masih sedikit dikembangkan. Kondisi ini disebabkan karena sistem tanam baru membutuhkan tenaga trampil, biaya pengolahan tanah yang lebih mahal dan terbatasnya pengetahuan petani. Varietas lokal sudah lama ditinggalkan petani, saat ini beberapa VUB lebih banyak mendominasi pertanaman padi. Pertimbangan pemilihan varietas utamanya adalah karena produksi tinggi dan ketahanan terhadap penyakit. Selain itu, kemudahan petani dalam memperoleh benih padi di toko pertanian terdekat juga menjadi pertimbangan. Oleh karena itu, upaya pendampingan yang lebih intensif baik melalui pertemuan kelompok tani dan perbaikan sarana pendukung sangat penting. Pemerintah daerah perlu meningkatkan keterjangkauan petani terhadap benih bermutu.
\end{abstract}

Kata kunci: sistem tanam, varietas padi, Kabupaten Pemalang

\begin{abstract}
Increasing rice productivity has been the main priority for the Government of Indonesia to meet people's food needs, however, there are a number of obstacles such as technology adoption. This study aims to explore the condition of farmers' cultivation, especially in terms of planting systems, varieties developed and reasons for selecting varieties in three different land topographic types (low, medium, and high). Sampling was done purposely with a total sample of 45 farmers who cultivate rice. Data collection includes observation and structured interview, data were analyzed descriptively. The results showed that most of the planting system that developed in three types of topography is the 'tegel' planting system, other technologies such as "jajar legowo" and system of rice intensification (SRI) have low developed. This is influenced by the new planting system need more skilled labor, more expensive input, and lack of farmers' knowledge. Local rice varieties have declined significantly, dominated by certain superior varieties. The main reason for selecting varieties is due to high productivity and disease resistance. In addition, the accessibility of rice
\end{abstract}


seeds by farmers at the nearest farm shop. This research suggested more intensive mentoring efforts should be done through farmers' group meetings and improvement of supporting facilities, furthermore the Local Government should improve farmers' affordability of quality seeds.

Keywords: planting system, rice varieties, Pemalang Regency

\section{PENDAHULUAN}

Indonesia menjadi negara dengan konsumsi domestik beras terbesar ketiga di dunia, dengan besaran pengeluaran dari tahun 2014-2018 meningkat sebesar 6.6 persen (Sabarella, 2019). Pada tahun 2018 konsumsi beras sebesar 80,65 kg/kap/ tahun (BPS, 2019a), cenderung menurun selama dua puluh tahun terakhir, namun pertambahan jumlah penduduk diproyeksikan terus meningkat 1,36 persen per tahun (BPS, 2013), artinya total konsumsi domestik diperkirakan akan meningkat. Oleh karena itu program peningkatan produksi padi masih menjadi prioritas. Disisi lain, target swasembada padi juga masih mengalami sejumlah kendala diantaranya terkait masih rendahnya tingkat adopsi inovasi pertanian. Teknologi memiliki peran sangat penting dalam peningkatan produksi dan bagaimana teknologi diadopsi (Gonzales et.al., 2009, Tiamiyu, 2009).

Kabupaten Pemalang merupakan salah satu daerah sentra penanaman padi di Provinsi Jawa Tengah. Secara nasional, Jawa Tengah menjadi penyumbang terbesar produksi beras yaitu sebesar 9.655.653,98 ton atau 17,68 persen dari total produksi nasional (BPS, 2020). Pada tahun 2018, luas panen padi di Kabupaten Pemalang mencapai 74,821 ha, produksi 360.242 kwintal dan produktivitas 48,15 $\mathrm{kw} / \mathrm{ha}$. Jika dibandingkan dengan rata-rata Jawa Tengah dan nasional produktivitas masih rendah (BPS, 2019b, BPS, 2020). Sementara, potensi produksi sejumlah varietas unggul dapat mencapai 8 ton/ha (Satoto, et.al., 2013), artinya masih terdapat peluang untuk meningkatkan produksi padi di Kabupaten Pemalang. Selain itu, meskipun secara geografis Kabupaten Pemalang terletak di daerah pantura Jawa, namun memiliki topografi yang beragam karena sebagian wilayahnya juga berada di kawasan pegunungan (Gunung Slamet), sehingga terbagi menjadi tiga yaitu dataran rendah, sedang dan tinggi (BPS,2019c). Padi ditanam bukan hanya di daerah dataran rendah, tetapi juga di daerah menengah dan tinggi.

Tulisan ini melengkapi publikasi sebelumnya dengan lokasi dan responden yang sama. Penelitian tersebut menunjukkan bahwa produktivitas padi di dataran rendah ternyata lebih tinggi dibandingkan dengan dataran medium dan tinggi, hal ini juga sejalan dengan keuntungan usahatani yang diperoleh (Handayani, 2017). Namun dalam tulisan tersebut belum diuraikan bagaimana teknologi budidaya khususnya terkait sistem tanam dan varietas padi yang dikembangkan oleh petani. Sejumlah penelitian menunjukkan bahwa pengaturan sistem tanam jajar legowo 4:1 terbukti meningkatkan produksi tanaman jika dibandingkan dengan sistem tanam tegel yang berkembang saat ini (Witjaksono, 2018, Sari et. al., 2014., Anggraini et.al. 2013, Putra, 2011). Selain itu, sejumlah varietas unggul baru (VUB) yang dihasilkan saat ini memiliki potensi produksi yang tinggi (Widjayanti et.al.,2011) namun belum banyak diintroduksi oleh petani. Oleh karena itu, penelitian ini bertujuan untuk mengetahui lebih jauh kondisi budidaya petani setempat terutama dari sisi sistem tanam dan varietas yang dikembangkan serta 
alasan pemilihan varietas oleh petani. Hasil studi diharapkan dapat memberikan referensi untuk peningkatan produksi padi khususnya di Kabupaten Pemalang dan di wilayah lainnya dengan karakteristk yang serupa.

\section{METODE PENELITIAN}

Penelitian ini adalah penelitian deskriptif yang menggunakan pendekatan kuantitatif. Penelitian deskriptif pencarian fakta dengan intrepertasi yang mempelajari masalah-masalah dalam masyarakat, serta tatacara yang berlaku dalam masyarakat serta situasi-situasi tertentu termasuk mengenai hubungan kegiatankegiatan, sikap, pandangan dan proses yang sedang berlangsung dan pengaruhpengaruh dari suatu fenomena (Whitney (1960) dalam Nazir 1988). Selain itu, pengumpulan data berdasarkan pada faktor-faktor yang menjadi pendukung terhadap objek penelitian, kemudian faktor-faktor tersebut dianalisa untuk mencari peranannya (Arikunto dan Suharsimi, 2010).

Penelitian dilaksanakan pada bulan Juli sampai dengan September 2016. Lokasi penelitian di Kabupaten Pemalang Jawa Tengah. Pemilihan lokasi dilaksanakan secara purposif yaitu di tiga desa yang merupakan daerah sentra padi dengan topografi yang berbeda, mewakili dataran rendah, medium dan tinggi. Pembagian 3 desa sampel sebagai berikut: 1) 0 - $200 \mathrm{~m}$ dpl: Desa Sirangkang
Kecamatan Petarukan, 2) 200-500 m dpl: Desa Kalimas Kecamatan Randudongkal, 3) Lebih dari 500 mdpl di Desa Walangsanga Kecamatan Moga. Pengambilan sampel dilakukan secara purposif berdasarkankan pada pertimbangan bahwa kondisi dan aktifitas usahatani yang dilakukan oleh petani di daerah penelitian relatif sama atau homogen (Nazir, 1988). Jumlah responden 45 petani yang membudidayakan padi atau 15 orang petani ditiap desa sampel.

Teknik pengumpulan data dilaksanakan dengan metode survey, yaitu penelitian yang memanfaatkan informasi dan data primer yang diperoleh secara langsung dari subyek yang diteliti melalui wawancara dengan menggunakan pertanyaan-pertanyaan yang terstruktur dalam kuesioner. Data yang terkumpul kemudian ditabulasi dan dianalisis secara deskriptif. Pengolahan data dilakukan dengan menggunakan metode diskriptif sesuai dengan tujuan penelitian.

\section{HASIL DAN PEMBAHASAN}

\section{Deskripsi Responden Penelitian}

Responden penelitian berjumlah 45 orang atau terdapat 15 responden petani di tiap desa, berikut ditampilkan deskripsi responden pada Tabel 1. Deskripsi responden meliputi jenis kelamin, umur, tingkat pendidikan, pengalaman usahatani, luas lahan dan jumlah tanggungan keluarga. 
Tabel 1.

Deskripsi Responden Penelitian di tiga desa lokasi penelitian

\begin{tabular}{|c|c|c|c|c|c|c|c|}
\hline \multirow[t]{2}{*}{ No } & \multirow[t]{2}{*}{ Uraian } & \multicolumn{2}{|c|}{ Sirangkang } & \multicolumn{2}{|c|}{ Kalimas } & \multicolumn{2}{|c|}{ Walangsanga } \\
\hline & & $\mathrm{n}$ & $\%$ & $\mathrm{n}$ & $\%$ & $\mathrm{n}$ & $\%$ \\
\hline \multirow[t]{3}{*}{1} & Jenis Kelamin & & & & & & \\
\hline & Laki-laki & 15 & 100,00 & 11 & 73,33 & 15 & 100,00 \\
\hline & Perempuan & 0 & - & 4 & 26,67 & 0 & - \\
\hline \multirow[t]{6}{*}{2} & Umur & & & & & & \\
\hline & $16-25$ & 0 & - & 0 & - & 0 & - \\
\hline & $26-35$ & 0 & - & 1 & 6,67 & 1 & 6,67 \\
\hline & $36-45$ & 3 & 20,00 & 4 & 26,67 & 1 & 6,67 \\
\hline & $46-55$ & 9 & 60,00 & 2 & 13,33 & 7 & 46,67 \\
\hline & $>55$ & 3 & 20,00 & 8 & 53,33 & 6 & 40,00 \\
\hline \multirow[t]{6}{*}{3} & Tingkat Pendidikan & & & & & & \\
\hline & TS & 0 & - & 2 & 13,33 & 1 & 6,67 \\
\hline & SD & 7 & 46,67 & 9 & 60,00 & 8 & 53,33 \\
\hline & SMP & 3 & 20,00 & 1 & 6,67 & 3 & 20,00 \\
\hline & SMA & 3 & 20,00 & 3 & 20,00 & 3 & 20,00 \\
\hline & DIII/PT & 2 & 13,33 & 0 & - & 0 & - \\
\hline \multirow[t]{6}{*}{4} & Pengalaman Usahat & ani 1 & & & & & \\
\hline & $<5$ th & 1 & 6,67 & 0 & - & 2 & 13,33 \\
\hline & $5-10$ th & 3 & 20,00 & 4 & 26,67 & 0 & - \\
\hline & $10-15$ th & 0 & - & 1 & 6,67 & 0 & - \\
\hline & $15-20$ th & 3 & 20,00 & 2 & 13,33 & 5 & 33,33 \\
\hline & $>21$ & 8 & 53,33 & 8 & 53,33 & 8 & 53,33 \\
\hline \multirow[t]{6}{*}{5} & Luas Lahan & & & & & & \\
\hline & $<0.5$ ha & 7 & 46,67 & 9 & 60,00 & 6 & 40,00 \\
\hline & $0.5-1$ ha & 6 & 40,00 & 5 & 33,33 & 7 & 46,67 \\
\hline & $1-2$ ha & 1 & 6,67 & 1 & 6,67 & 0 & - \\
\hline & $2-3$ ha & 0 & - & 0 & - & 2 & 13,33 \\
\hline & $>4$ ha & 1 & 6,67 & 0 & - & 0 & - \\
\hline \multirow[t]{7}{*}{6} & Jumlah Tanggungan & $\mathrm{Ke}$ & & & & & \\
\hline & 0 & 0 & - & 2 & 13,33 & 2 & 13,33 \\
\hline & 1 & 3 & 20,00 & 6 & 40,00 & 2 & 13,33 \\
\hline & 2 & 1 & 6,67 & 1 & 6,67 & 3 & 20,00 \\
\hline & 3 & 3 & 20,00 & 6 & 40,00 & 5 & 33,33 \\
\hline & 4 & 6 & 40,00 & 0 & - & 2 & 13,33 \\
\hline & $>5$ & 2 & 13,33 & 0 & - & 1 & 6,67 \\
\hline
\end{tabular}

Sumber: Data primer diolah 2016

Responden penelitian di Desa Sirangkang dan Walangsanga sebagian besar adalah laki-laki. Secara umum, Di Desa Sirangkang semua reponden berumur di atas 36 tahun dengan proporsi terbesar di antara 46-55 tahun (60\%). Responden petani di Desa Kalimas sebagian besar atau 53 persennya berumur diatas 55 tahun, sementara di Desa
Walangsanga 86 persen responden berusia di atas 46 tahun.

Tingkat pendidikan responden petani pada ketiga desa rata-rata masih rendah atau hanya berpendidikan SD. Responden di Desa Sirangkang memiliki pendidikan yang lebih baik dibandingkan Desa Kalimas dan Walangsanga. Meskipun demikian, rata-rata 
responden memiliki pengalaman usahatani yang lama sehingga banyak petani yang memperoleh pengetahuan secara informal. Sebagian besar responden pada ketiga lokasi memiliki pengalaman usahatani diatas 21 tahun yaitu masing-masing sejumlah 53 persen yang artinya sudah sangat berpengalaman dalam budidaya padi. Petani pemula dengan rentang pengalaman kurang dari sepuluh tahun di Desa Sirangkang dan Kalimas sekitar 26persen Sementara petani pada rentang pengalaman 15-20 tahun terbanyak di desa Walangsanga yaitu mencapai 33 persen.

Luas lahan yang dimiliki petani di ketiga lokasi sebagian besar $<0,5$ ha dan antara 0,5- 1 ha. Desa Kalimas memiliki luasan lahan $<0,5$ ha yang tertinggi ( $60 \%$ ), sementara Desa Walangsanga petani memiliki luasan lahan antara 0,5-1 ha lebih tinggi dibanding desa lainnya. Petani dengan kepemilikan lahan $>4$ ha hanya ada satu yaitu di Desa Sirangkang. Luasan lahan seringkali berpengaruh terhadap cara-cara petani dalam mengadopsi sejumlah teknologi budidaya.
Distribusi jumlah tanggungan keluarga pada ketiga lokasi bervariasi, di Desa Sirangkang 40 persen memiliki jumlah tanggungan keluarga 4 orang, di Desa Kalimas semuanya kurang dari 4 dan di Desa Walangsanga cukup merata dengan tanggungan keluarga tertinggi 3 orang sekitar 33 persen. Jumlah tanggungan keluarga mempengaruhi motivasi ekonomi petani untuk meningkatkan pendapatan agar dapat memenuhi kebutuhan rumahtangganya.

\section{Penerapan Sistem Tanam di Tiga Tipe Topografi}

Hasil survey ditampilkan pada Tabel 2 menunjukkan bahwa sistem tanam yang berkembang di ketiga tipe topografi lahan sebagian besar masih menggunakan sistem tanam tegel atau masih tradisional. Secara berturut-turut, di Desa Sirangkang 80 persen petani, Desa Kalimas 86 persen petani dan di Desa Walangsanga 73,33 persen petani. Penerapan sistem tanam baru seperti jajar legowo dan SRI masih sangat sedikit $<25$ persen disemua lokasi.

Tabel 2.

Sistem tanam yang dikembangkan petani di tiga tipe topografi pada agroekosistem padi sawah di Kabupaten Pemalang

\begin{tabular}{lcccccc}
\hline \multirow{2}{*}{ Sistem tanam } & \multicolumn{2}{c}{ Sirangkang } & \multicolumn{2}{c}{ Kalimas } & \multicolumn{2}{c}{ Walangsanga } \\
& $\mathrm{n}$ & $\%$ & $\mathrm{n}$ & $\%$ & $\mathrm{n}$ & $\%$ \\
\hline Tegel & 12 & 80,00 & 13 & 86,67 & 11 & 73,33 \\
Jajar legowo & 3 & 20,00 & 1 & 6,67 & 4 & 26,67 \\
SRI & - & - & 1 & 6,67 & - & - \\
\hline \multicolumn{1}{c}{ Jumlah } & 15 & 100,00 & 15 & 100,00 & 15 & 100,00 \\
\hline
\end{tabular}

Sumber: Data primer diolah 2016

Sistem tanam tegel merupakan sistem tanam yang secara turun temurun dikembangkan petani. Secara umum petani sudah terbiasa dengan sistem tanam ini dan hasil oberservasi menunjukkan hampir 90 persen pada pertanaman padi masih menggunakan sistem tegel. Selain sistem tanam tegel, sistem tanam dengan metode jajar legowo juga sudah dikenal petani terutama melalui penyuluhan oleh PPL.

Sistem tanam jajar legowo bertujuan untuk meningkatkan populasi tanaman per satuan luas. Ada beberapa tipe cara tanam sistem jajar legowo yang secara umum dapat dilakukan yaitu; tipe legowo $(2: 1),(3: 1)$, (4: 1), (5:1), (6:1) dan tipe lainnya yang sudah ada serta telah diaplikasikan oleh sebagian masyarakat petani di Indonesia. Namun berdasarkan penelitian yang dilakukan di Balai Pengkajian Teknologi Pertanian (BPTP Jambi, 2013) diketahui jika tipe sistem tanam jajar legowo terbaik dalam memberikan hasil produksi gabah tinggi adalah tipe jajar legowo (4:1) sedangkan dari tipe jajar legowo (2:1) 
dapat diterapkan untuk mendapatkan bulir gabah berkualitas benih. Berdasarkan hasil yang diperoleh terdapat peningkatan produksi mencapai 30 persen menggunakan sistem jajar legowo jika dibandingkan dengan sistem tanam tegel.

Di Desa Walangsanga jajar legowo dikenalkan semenjak tahun 2011 dengan luasan lahan percontohan 2 ha, tahun 2013 dan 2014 masing-masing 20 ha, bantuan pembiayaan yang diberikan sebesar 2 juta /ha. Sementara di Desa Kalimas penerapan sistem ini memang belum banyak dikembangkan, sejumlah petani responden beranggapan bahwa lajur kosong yang dibiarkan pada sistem jajar legowo akan mengurangi produksi yang diperoleh. Namun pada saat survey dilaksankan tahun 2016, Penyuluh (PPL) telah menargetkan akan melaksanakan peningkatan sistem ini sampai menjadi 60 persen. Sistem tanam jajar legowo ini sudah diperkenalkan oleh PPL semenjak lima tahun terakhir namun penerapan sistem tanam tersebut belum optimal. Melalui observasi lapang hampir 90 persen sistem tanam yang digunkan masih siste tanam tegel.

Dari hasil wawancara mendalam dengan sejumlah responden, terdapat beberapa alasan kenapa masih sedikit petani yang menerapkan system jajar legowo, berikut sejumlah persepsi petani terkait penanaman sistem jajar legowo:(1) Jumlah tenaga kerja lebih tinggi dan waktu penanaman lebih lama, (2) Membutuhkan benih dan bibit yang lebih tinggi karena adanya penambahan populasi tanaman, (3) Pada baris kosong jajar legowo biasanya akan ditumbuhi lebih banyak rumput/gulma, (4) Sistem tanam jajar legowo yang diterapkan pada lahan yang kurang subur akan meningkatkan jumlah penggunaan pupuk meskipun masih dalam tingkat signifikasi yang rendah, (5) Konsekuensi dari waktu, tenaga dan kebutuhan benih yang lebih tinggi maka jumlah biaya yang dibutuhkan semakin meningkat.

Sejumlah petani memiliki persepsi yang salah karena tingkat pengetahuan mengenai sistem jajar legowo masih kurang padahal berdasarkan dari sejumlah referensi bahwa sistem tanam jajar legowo memberikan peningkatan hasil (Witjaksono, 2018,
Suhendradata, 2017, Sari, et.al. 2014). Meskipun terdapat petani yang juga sudah menerapkan sistem tanam ini dan telah terbukti meningkatkan produksi, namun tidak dilanjutkan dengan pertimbangan biaya input produksi lebih tinggi karena tenaga kerja belum terlatih dalam melakukan sistem tanam jajar legowo. Petani umumnya tidak melakukan panen sendiri namun langsung dijual kepada pengepul sehingga besaran peningkatan produksi tidak diperhatikan namun sangat tergantung kepada estimasi pengepul.

Introduksi inovasi baru memang tidak mudah karena terdapat sejumlah kendala. Penelitian yang dilakukan oleh Setiawan dan Nastiti (2017) menunjukkan bahwa pengetahuan petani berpengaruh positif dan nyata terhadap motivasi petani. Motivasi petani berpengaruh positif dan sangat berpengaruh terhadap tingkat adopsi inovasi dengan menggunakan sistem tanam jajar legowo. Sementara peran PPL menjadi sangat penting dalam mengajak dan memberikan pemahaman kepada petani, karena kurangnya peran penyuluh berpengaruh terhadap tingkat adopsi (Hiola dan Indriana, 2018). Selanjutnya menurut Soekartawi (2005) bahwa beberapa hal yang penting dalam mempengaruhi adopsi inovasi antara lain: umur, pendidikan, keberanian mengambil resiko, pola hubungan, sikap terhadap perubahan, motivasi berkarya, aspirasi, fatalisme, sistem kepercayaan tertentu, karakteristik psikologi. Penelitian yang dilakukan oleh Sirnawati dan Sumedi (2019) menunjukkan bahwa adopsi teknologi juga sangat dipengaruhi oleh lingkungan sosial petani, yang dicerminkan oleh frekuensi mengikuti pelatihan dan pertemuan kelompok serta kemampuan ekonomi petani dalam mengakses sumber kredit permodalan. Kondisi sosial ekonomi yang beragam memerlukan metode diseminasi yang berbeda, sehingga diperlukan fleksibilitas metode dalam penyampaian teknologi.

\section{Varietas Padi yang Berkembang pada Tiga Tipe Topografi Agroekosistem Padi Sawah}


Varietas padi yang berkembang di tiga tipe topografi pada agroekosistem padi sawah sebagian besar merupakan varietas unggul, varietas lokal sudah sangat jarang ditemui.
Data jenis varietas padi unggul yang dibudidayakan petani ditampilkan pada Tabel 3 dan Tabel. 4.

Tabel 3.

Varietas unggul baru yang diadopsi petani

\begin{tabular}{|c|c|c|c|c|c|c|c|}
\hline \multirow[t]{2}{*}{ No } & \multirow[t]{2}{*}{ Varietas } & \multicolumn{2}{|c|}{ Sirangkang } & \multicolumn{2}{|c|}{ Kalimas } & \multicolumn{2}{|c|}{ Walangsanga } \\
\hline & & $\mathrm{n}$ & $\%$ & $\mathrm{n}$ & $\%$ & $\mathrm{n}$ & $\%$ \\
\hline$\overline{1}$ & Ciherang & 15 & 100 & & & & \\
\hline 2 & Situbagendit & & & 6 & 40,00 & 2 & 13,33 \\
\hline 3 & Mekonga & & & 5 & 33,33 & 3 & 20,00 \\
\hline 4 & IR 64 & & & 3 & 20,00 & 4 & 26,67 \\
\hline 5 & Rojolele & & & & & 3 & 20,00 \\
\hline 6 & Way Opu Buru & & & 1 & 6,67 & & \\
\hline 7 & Pusaka & & & & & 2 & 13,33 \\
\hline 8 & Fatmawati & & & & & 1 & 6,67 \\
\hline \multirow[t]{2}{*}{9} & $\begin{array}{l}\text { Lainnya ( } 4 \text { varietas): } \\
\text { Black Madras, } \\
\text { Kalina, Jelita, Najwa }\end{array}$ & & & 1 & 6,67 & & \\
\hline & & 15 & 100 & 15 & 100 & 15 & 100 \\
\hline
\end{tabular}

Sumber: Data primer 2016 diolah

Tabel 4.

Varietas unggul padi yang diadopsi petani berdasarkan musim tanam

\begin{tabular}{llll}
\hline \multirow{2}{*}{ Musim } & \multicolumn{3}{c}{ Desa } \\
\cline { 2 - 4 } & \multicolumn{1}{c}{ Sirangkang } & \multicolumn{1}{c}{ Kalimas } & \multicolumn{1}{c}{ Walangsanga } \\
\hline Musim Hujan (Ok- & Ciherang & Mekongga, Black & Rojolele, Mekongga, \\
Maret) & & $\begin{array}{l}\text { Madras, Jelita, Najwa, } \\
\text { Kalina, Way Opo Buru }\end{array}$ & Fatmawati \\
Musm Kemarau & Ciherang & Situ Bagendit, & IR 64, Pusaka \\
(April-Sept) & & Mekongga, IR 64 & \\
\hline
\end{tabular}

Sumber data primer 2016

Pada daerah dataran rendah (Desa Sirangkang) petani menanam padi varietas Ciherang baik di musim hujan maupun di musim kemarau. Sebelumnya petani banyak menanam IR 64 namun banyak serangan hama dan penyakit terutama pada musim hujan sehingga saat ini mayoritas petani beralih ke varietas ciherang. Pertimbangan petani memilih varietas ini adalah karena dapat berproduksi tinggi, lebih tahan terhadap penyakit dan memiliki rasa nasi yang pulen. Secara genetis varietas Ciherang memiliki umur tanam antara 116-125 hari. Tinggi tanaman 107- $115 \mathrm{~cm}$. Potensi hasil mencapai 5-7 ton/ha. Beras Ciherang memiliki keunggulan tahan terhadap wereng batang coklat biotipe 2 dan 3. Tahan terhadap hawar daun bakteri patotipe III dan IV. Baik ditanam pada musim hujan dan kemarau di bawah ketinggian $500 \mathrm{mdpl}$.

Di dataran menengah, Desa Kalimas varietas yang banyak dibudidayakan adalah situbagendit (40\%), mekongga (33\%) dan IR $64(20 \%)$. Beberapa petani atau sekitar 13 persennya juga mulai mencoba beberapa varietas unggul baru seperti way opu boru, 
jelita, najwa, kalina, Black Madras. Pengembangan varietas tersebut masih sangat sedikit karena varietas tersebut tidak dijual di toko pertanian terdekat tapi harus dipesan terlebih dahulu.

Varietas padi Black Madras berasal dari Korea yang dari sisi morfologinya cukup unik karena memiliki warna yang berbeda dibanding varietas padi pada umumnya. Black Madras berwarna coklat sedikit ke merah marun atau memiliki warna burgundi. Untuk hasil produksi belum diketahui karena baru pertama kali ditanam pada saat survey penelitian padi sudah 28 hari ditanam sementara umur panennya tergolong pendek hanya 95 hari dengan harga benih sekitar 120 ribu dan dipesan secara online. Petani yang mengembangkan varietas ini adalah Bapak Syafaat Ketua Kelompok Tani Citra Langgeng I. Namun varietas unggul baru yang lain seperti najwa mampu berproduksi sampai dengan 12 ton/ha.

Di dataran tinggi di Desa Walangsanga varietas yang paling banyak ditanam adalah IR 64 (26\%), Rojolele (20\%), Mekongga (20\%), Situbagendit dan Pusaka masing-masing 13 persen dan padi varietas unggul baru Fatmawati. Rojolele dan Mekongga banyak ditanam saat musim hujan dan di musim kemarau petani lebih menyukai varietas IR 64 dan Pusaka. IR 64 merupakan varietas padi yang sudah dirilis semenjak tahun 1986 oleh Kementan dan sampai saat ini masih banyak dibudidayakan petani meskipun di sejumlah wilayah IR 64 banyak digantikan dengan varietas ciherang.

Penyebab utama pergeseran dari varietas IR64 ke varietas unggulan baru (VUB) erat kaitannya dengan produktivitas dan ketahanannya terhadap hama penyakit. Namun, bagi sebagian besar petani di Desa Walangsanga IR 64 masih sangat disukai karena memiliki tekstur nasi yang pulen. Secara umum, petani di Desa Walangsanga lebih banyak memanen padi sendiri dan selanjutnya diproses untuk kebutuhannya sendiri kurang lebih hampir 90 persen petani, sementara sisanya dijual ke pengepul.
Apabila dilihat dari sebaran varietas yang ditanam pada ketiga lokasi terdapat tiga varietas yang cukup populer yaitu Ciherang, IR 64, Mekongga dan Situ Bagandit. Padahal terdapat puluhan VUB baru yang dikembangkan namun petani belum tertarik untuk mencoba varietas lainnya. Varietas Situ Bagendit merupakan varietas padi yang dapat ditanam baik pada lahan kering maupun lahan sawah. Dengan umur panen 110-120 hari, varietas ini diketahui memiliki ketahanan terhadap penyakit blas dan hawar daun bakteri patotipe III dan IV. Rata-rata hasil 3-5 ton. Tekstur nasi pulen, dengan kadar amilosa 22 persen, secara morfologi memiliki tinggi tanaman 99-105 mm.

Varietas mekongga di Kabupaten Pemalang diperkenalkan semenjak tahun 2008 yang kemudian banyak berkembang di dataran menengah sampai tinggi. Secara genetis memiliki umur tanam 106-125 hari. Bentuk tanaman sedang dengan tinggi 91-106 cm, memiliki daun bendera tegak. Bentuk gabah ramping panjang dengan warna gabah kuning bersih dan tingkat kerontokan sedang. Tekstur nasi pulen, memiliki kadar amilosa 23\%, indeks glikemik 88. Berat 1000 butir sekitar 27-28 gram. Potensi hasil 6 ton/ha GKG. Varietas ini agak peka terhadap wereng coklat biotipe 2 dan 3 dan Agak peka terhadap hawar daun bakteri strain IV. Baik ditanam di sawah dataran rendah sampai ketinggian $500 \mathrm{~m}$ dpl.

Varietas lokal sudah sangat jarang dibudidayakan petani, dan saat ini petani memilih varietas unggul baru yang memiliki waktu panen lebih singkat. Kondisi ini juga disebabkan karena kemudahan petani dalam memperoleh varietas-varietas unggul di kioskios tani, sementara varietas lokal sudah menghilang kecuali petani memiliki cadangan benih untuk musim tanam berikutnya. Pemilihan varietas yang dikembangkan lebih banyak berdasarkan kepada pengalaman usahatani sebelumnya. Terdapat sejumlah pertimbangan petani di lokasi penelitian dalam memilih varietas yang dikembangkan, data ditampilkan pada Tabel 5. 
Tabel 5.

Pertimbangan Pemilihan Varietas

\begin{tabular}{lllccccc}
\hline \multirow{2}{*}{ No } & $\begin{array}{l}\text { Pertimbangan pemilihan } \\
\text { varietas }\end{array}$ & \multicolumn{2}{c}{ Sirangkang } & \multicolumn{2}{c}{ Kalimas } & \multicolumn{2}{c}{ Walangsanga } \\
\cline { 2 - 7 } & $\mathrm{n}$ & $\%$ & $\mathrm{n}$ & $\%$ & $\mathrm{n}$ & $\%$ \\
\hline 1 & Turun temurun & & & 1 & 6,67 & 3 & 20 \\
2 & $\begin{array}{l}\text { Produksi lebih tinggi } \\
\text { Ketahanan terhadap hama }\end{array}$ & 12 & 80 & 8 & 53,33 & 5 & 33,33 \\
3 & 3 & 20 & 5 & 33,33 & 2 & 13,33 \\
& dan penyakit & & & & & & \\
4 & Nasih lebih pulen & & & 2 & 13,33 & 5 & 33,33 \\
\hline & Jumlah & 15 & 100 & 15 & 100,00 & 15 & 100 \\
\hline
\end{tabular}

Sumber: Data Primer 2016 diolah

Pertimbangan pemilihan varietas ditiap tipe topografi pada umunya mencari varietas yang mampu berproduksi tinggi. Di daerah dataran rendah produksi lebih tinggi menjadi alasan utama dalam memilih varietas padi, sekitar 80 persen petani sementara sisanya karena ketahanan terhadap penyakit. Didataran menengah, Desa Kalimas produksi menjadi alasan utama (53\%), ketahanan terhadap penyakit 33 persen dan 20 persen karena sudah dibudidayakan secara turun temurun dan rasa yang pulen. Di Desa Walangsanga produksi dan rasa yang pulen menjadi pertimbangan utama (masing-masing $33 \%$ ) karena hasil panen padi sebagian besar untuk dikonsumsi sendiri.

\section{KESIMPULAN}

berikut:

Kesimpulan penelitian ini sebagai

1. Sistem tanam yang berkembang di tiga tipe topografi agroekosistem padi sawah adalah sistem tanam tegel. Beberapa teknologi seperti jajar legowo dan SRI sudah introduksi ke petani namun sedikit petani yang mau untuk terus mengembangkan dan kembali ke sistem tanam semula. Kondisi ini disebabkan karena sistem tanam baru membutuhkan tenaga trampil dan biaya pengolahan tanah yang lebih mahal.

2. Varietas lokal sudah lama ditinggalkan petani, saat ini beberapa VUB populer mendominasi pertanaman padi pada ketiga lokasi desa sampel, yaitu: (a) Di dataran rendah hampir semua petani menanam varietas Ciherang, (b) Di dataran menengah (Desa Kalimas) lebih banyak jenis varietas yang dikembangkan. Sementara di daerah dataran tinggi, Desa Walangsanga varietas yang paling banyak ditanam adalah IR 64, Rojolele dan Mekongga.

3. Pertimbangan pemilihan varietas utamanya adalah karena produksi tinggi dan ketahanan terhadap penyakit (Desa Sirngkang dan Kalimas), namun di Desa Walangsanga rasa pulen menjadi pertimbangan yang sama dengan produksi karena sebagian besar hasil sawah petani digunakan untuk konsumsi sendiri. Selain itu, kemudahan petani dalam memperoleh benih padi di toko pertanian terdekat juga menjadi pertimbangan.

\section{SARAN}

1. Perlu upaya pendampingan yang lebih intensif dalam menerapkan sistem tanam baru dengan meningkatkan intensitas pertemuan kelompok dengan PPL, perbaikan sarana media pendukung yang digunakan dalam penyuluhan pertanian sehingga introduksi teknologi dapat menjangkau petani lebih luas.

2. Terdapat banyak varietas unggul baru (VUB) dengan produktivitas tinggi namun tingkat adopsi petani dalam memilih varietas sangat bergantung kepada keterjangkauan sumber benih tersebut sehingga Pemerintah melalui dinas teknis perlu meningkatkan ketersediaan benih bermutu. 


\section{DAFTAR PUSTAKA}

Anggraini, F., A.Suryanto, N. Aini, 2013. Sistem Tanam dan Umur Bibit Pada Tanaman Padi Sawah (Oryza Sativa L.) Varietas Inpari 13. Jurnal Produksi Tanaman Vol. 1 No. 2 Mei-2013.

Arikunto dan Suharsimi. 2010. Prosedur Penelitian: Suatu Pendekatan Praktik. Jakarta: Rineka Cipta).

BPS, 2013. Proyeksi Penduduk Indonesia 2010-2035. Kerjasama antara Bappenas, BPS dan UNSFA. ISBN: 978-979-064606-3.

BPS, 2019a. Rata-Rata Konsumsi per Kapita

Seminggu Beberapa Macam Bahan

Makanan Penting,2007-

2018.https://www.bps.go.id/statictable/ 2014/09/08/950/rata-rata- konsum si-

per-kapita-seminggu-beberapa-macambahan-makanan-penting-2007-

2018.html. Diakses pada Juli 2020.

BPS, 2019b. Jawa Tengah dalam Angka Tahun 2019.

BPS, 2019c. Kabupaten Pemalang dalam Angka Tahun 2019.

BPS, 2020. Statistik Indonesia Dalam Infografis 2020.

BPTP Jambi, 2013. Sistem Tanam Jajar Legowo.Balai Besar Pengkajian Dan Pengembangan Teknologi Pertanian Badan Penelitian Dan Pengembangan Pertanian Kementerian Pertanian.

González, V., P. Ibarrarán, A. Maffioli, and S. Rozo, 2009. The Impact of Technology Adoption on Agricultural Productivity: The Case of the Dominican Republic. IDB Publications (Working Papers) 3017, Inter-American Development Bank.

Handayani, A., 2017. Studi Komparasi Usahatani Padi di Tiga Tipe Topografi di Kabupaten Pemalang. Prosiding Seminar Nasional Tahun 2017. Inovasi dan Kreasi Memajukan Jawa Tengah. Semarang 14-15 Desember 2017. Diterbitkan oleh Badan Perencanaan Pembangunan, Penelitian dan Pengembangan Daerah (BAPPEDA) Provinsi Jawa Tengah. ISBN 978-602-8916-33-2.
Hiola N.A. dan Indriana, 2018. Tingkat Adopsi Inovasi Sistem Tanam Jajar Legowo Pada Tanaman Padi Di Desa Ilomangga Kecamatan Tabongo Kabupaten Gorontalo. Jurnal Agropolitan Volume 5 Nomor 1 Bulan Juli 2018. Hal 53-62.

Nasir, M. 1988. Metode Penelitian. Ghalia Indonesia

Putra, S., 2011. Pengaruh Jarak Tanam Terhadap Peningkatan Hasil Padi Gogo Varietas Situ Patenggang. Agrin Vol. 15, No. 1, April 2011

Sari, D.N. Sumardi dan E. Suprijono, 2014. Pengujian Berbagai Tipe Tanam Jajar Legowo terhadap Hasil Padi Sawah Akta Agrosia Vol. 17 No. 2 hlm 115 124 Juli - Desember 2014 ISSN 14103354

Sabarella, 2019. Konsumsi Dan Neraca Penyediaan - Penggunaan Beras. Pusat Data dan Sistem Informasi Pertanian, Sekretariat Jenderal, Kementrian Pertanian. Buletin Konsumsi Pangan, Vol 10, No 1 Tahun 2019. Hal 11-22.

Satoto, M.J. Mejaya, Y. Widyastuti, dan I. A. Rumanti, 2013. Stabilitas dan Potensi Hasil Varietas Unggul Baru Padi Hibrida. Penelitian Pertanian Tanaman Pangan Vol. 32 No. 22013.

Soekartawi. 2005. Prinsip Dasar Komunikasi Pertanian. UI Press. Jakarta. $137 \mathrm{hlm}$.

Setiawan, I.G.B.D. dan N.W.S. Astiti, 2017. Faktor-Faktor Yang Mempengaruhi Adopsi Inovasi Sistem Tanam Jajar Legowo 2:1 Di Subak Penyaringan, Kecamatan Mendoyo, Kabupaten Jembrana. Jurnal Manajemen Agribisnis Vol.5, No.2, Oktober 2017. Hal 1-6.

Sirnawati, E. dan Sumedi, 2019. Faktor Penentu Adopsi Paket Teknologi Jajar Legowo Super:Studi Kasus di Sentra Produksi Padi Nasional. Penelitian Pertanian Tanaman PanganVol. 3 No. 3 Desember 2019: 143-152

Suhendrata, T., 2017. Pengaruh Jarak Tanam Pada Sistem Tanam Jajar Legowo Terhadap Pertumbuhan, Produktivitas Dan Pendapatan Petani Padi Sawah Di Kabupaten Sragen Jawa Tengah. SEPA (Jurnal Sosial Ekonomi Pangan dan 
Bisnis), Vol 13, No 2 (2017). DOI: https://doi.org/10.20961/sepa.v13i2.210 $\underline{30}$

Tiamiyu, S.A., J.O. Akintola dan M.A.Y. Rahji, 2009. Technology Adoption and Productivity Difference among Growers of New Rice for Africa in Savanna Zone of Nigeria. Tropicultura, 2009, 27, 4, 193-197.

Witjaksono, J. 2018. Kajian Sistem Tanam Jajar Legowo untuk Peningkatan
Produktivitas Tanaman Padi di Sulawesi Tenggara. Pangan. Vol. 27 No. 1 April 2018. Hal 1-8. 10.33964/jp.v27i1.400

Widyayanti, S. Kristamtini dan Sutarno, 2011. Daya Hasil Tiga Varietas Unggul Baru Padi Sawah Di Kebon Agung. Widyariset, Vol. 14 No.3, Desember 2011 